\title{
Tax Reform for Pakistan: Overview and Effective Taxes for 1975-76
}

\author{
EHTISHAM AHMAD and NiCHOLAS STERN*
}

\begin{abstract}
This paper evaluates consequences of taxation policy changes in-terms of effects on government revenue, households and production. It concentrates on derivation and analysis of effective taxes. The revised economy-wide input-output table prepared at the Pakistan Institute of Development Economics has been used to estimate effective taxes and shadow prices. The paper finds that in Pakistan as in other developing countries effective tax rates diverge substantially from nominal tax rates - a fact whose awareness can greatly help the policy-makèrs in avoiding unintended consequences of government policies.
\end{abstract}

\section{INTRODUCTION}

The question of appropriate sources of additional revenue is of central importance to many developing countries, including Pakistan. In this paper we evaluate the consequences of policy changes in terms of the effects not only on revenue but also on households in different circumstances and on production, using an approach which provides a general method of looking at policy. We set out this theory of marginal tax reform in Section 2 . In earlier works $[2 ; 5]$ we developed an analysis which concentrated on the effects of tax changes on households and government revenue. Here we use the techniques of social cost-benefit analysis $[7 ; 4]$ to allow the production side a more prominent role, thus integrating shadow prices into the analysis of tax reform.

The appraisal of different policies requires calculation of their effects, and in Section 3 of this paper we use an input-output model of production in the Pakistani economy to examine how taxes on intermediate goods work through to the prices

*Ehtisham Ahmad is Principal Research Fellow and Deputy Director of Development Economics Research Centre, University of Warwick, and Nicholas Stern is Professor of Economics at the London School of Economics. This paper forms part of the work of the project on the Tax Systems of Pakistan and Mexico directed by Ehtisham Ahmad, Jesus Seade and Nicholas Stern, and supported by funds from the UK Economic and Social Research Council (ESRC) and the World Bank under RPO 673-13. The authors are very grateful to Jean Dreze, Khalil Hamdani, Nizar Jetha, Jeffery Round, Jesus Seade, Asghar Qadir and Arshad Zaman for advice and helpful comments. All errors are of the authors and the opinions expressed here are not necessarily those of the ESRC or the World Bank. 
of final products. The tax element in the price of final goods is called, in this context, the "effective tax" and is an essential ingredient of our analysis of reform. The results suggest that in Pakistan, as in some other developing countries, effective taxes diverge substantially from the taxes nominally associated with particular groups of commodities. Thus, for instance, commodities which are not taxed directly may be effectively taxed through taxation of intermediate goods. It may be of interest to policy-makers to know how far nominal taxes on particular groups of commodities differ from "effective taxes".

Shadow prices are also estimated using the same economy-wide input-output table as for effective taxes. (Previous studies of shadow prices in Pakistan have not been able to adopt the economy-wide input-output approach; see [17] for example.) Again, whilst these are important to the analysis of reform, they are also of interest in themselves and are a guide to policy-makers in their decision to encourage certain sectors. These estimates are presented in a sequel to this paper.

The estimates of effective taxes and shadow prices are building blocks that will be used in our analysis of tax reform in Pakistan, using the theory described in Section 2. The results of that analysis will be presented in papers which will follow.

\section{THE THEORY OF TAX REFORM AND COST-BENEFIT ANALYSIS}

Given any proposed change, we ask how it affects the welfare of members of the community. A particularly useful concept here is the notion of a shadow price which is defined for a particular good as the opportunity cost, in terms of effects on social welfare, of making an extra unit of that good available from the system. ${ }^{1}$ A tax change will affect consumers directly through changes in the prices they face and this will result in changed demands. An appraisal of the change involves an evaluation of both the direct effects and the costs of the changed demands. We have a beneficial tax reform if the value to the community of the direct effects of the changed policies (e.g. from the lower prices for some goods and higher for others) is greater than the shadow value of the change in quantities of goods and factors which are the direct consequence of the policy change. The calculation of shadow prices is, therefore, an important step in the analysis of reform. In this subsection we set out formally this characterization of a beneficial reform and consider some special cases.

It is standard in partial-equilibrium analysis to look at a policy change in terms of its effects on consumers (usually through consumer surplus), producers (through profits) and governments (through net revenue). This decomposition can provide a

${ }^{1}$ Similarly one may define the shadow price of a good as the increase in social welfare which would result from an extra unit made available from outside the system. With appropriate differentiability properties the two definitions will have the same result and in this work we shall treat them as equivalent. 
useful intuitive framework and, with care, can be carried into a general-equilibrium discussion. We begin, therefore, with a brief description of the partial-equilibrium story to motivate the subsequent more general analysis. The discussion of the general approach is much influenced by Jean Dreze $[6 ; 7]$.

We examine a model with several goods but one which is partial equilibrium in the sense that we consider only 'first round' consequences of change and thus do not trace the changes in firms' profits and in factor incomes back to households. Let us consider a change $\Delta t$ in the tax vector $t$. This results in a change in the vector of quantities demanded $\Delta x$, and in consumer welfare $\Delta u$, in government revenue $\Delta R$ and in profits $\Delta \Pi$ (where we suppose output expands to meet the extra demand). Costs of production are $C(x)$ and we think of a single firm. Suppose that the vectors of producer prices, $p$, and consumer prices, $q$, are changed by $\Delta p$ and $\Delta q$ respectively and that the changes in revenue and profits are not fed back into the system. These partial-equilibrium assumptions will be relaxed in the general approach below and are made here to keep things simple and to provide an initial intuitive feel. Household $h$ has consumption vector $x^{h}$ where positive entries correspond to purchases and negative entries to sales. We have, as the change in consumer welfare,

$$
\Delta u=-\sum_{h} \beta^{h} x^{h} \cdot \Delta q
$$

where $\beta^{h}$ is the social marginal utility of income and $x^{h} \Delta q$ is a money measure of the loss in consumer surplus from the price increase $\Delta q$. If the vector of marginal costs of production is $c=(\partial c / \partial x)$ then profit changes are

$$
\begin{aligned}
\Delta \Pi & =\Delta p \cdot x+(p-c) \cdot \Delta x \\
& =\Delta(p \cdot x)-c \cdot \Delta x
\end{aligned}
$$

and since government revenue is tax times demand, the additional government revenue is

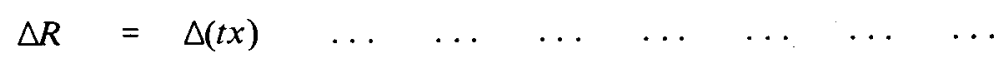

Forming an unweighted sum of the change in revenue and the change in profits, we have

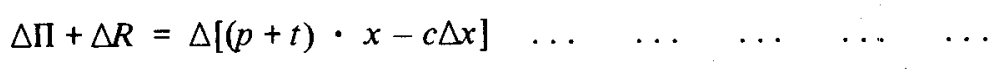

Bearing in mind that the consumer price is the sum of the producer price and tax, i.e.

$$
p+t=q
$$


and that we assume that total expenditure is fixed

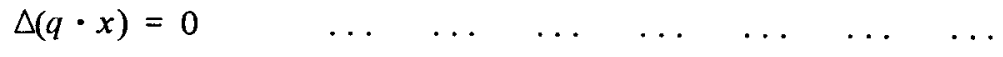

since we are assuming for this calculation that incomes are unchanged (i.e. $q \cdot x^{h}=$ constant for each household), we have

$$
\Delta \Pi+\Delta R=-c \Delta x \quad \ldots \quad \ldots \quad \ldots \quad \ldots \quad \ldots \quad \ldots \quad \ldots
$$

and total change in welfare $\Delta V$, if taken as an unweighted sum of the three elements $(\Delta u, \Delta \Pi$ and $\Delta R)$ is

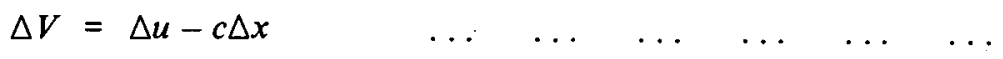

Thus to calculate the change in welfare we examine the direct effect $\Delta u$ on households of the price change $\Delta q$ and subtract the marginal costs of producing the changed demands. We saw how Eq. (2.8) could be decomposed into its constituent elements of changes in consumer welfare, revenue and profits. The formulation (2.8) and the decomposition carry over to more general models and help the understanding of the more complex cases in which $c$ stands for the marginal social costs of production or the shadow price vector. It then plays the role of capturing all the general-equilibrium consequences, including all the second-round changes ignored in the above discussion.

A particularly simple case arises where marginal (social) costs, $c$, are equal to producer prices, $p$ (taken to be constant). We then have zero change in profits and we need to examine only $V$ and $R$. In some of our earlier works we focused on these terms only but, as we have seen, this special case may be extended to include $\Delta \Pi$ and, as we shall now see, to more complicated models.

We take a fairly general model first and then consider some special cases. ${ }^{2}$ The government is concerned with the selection of certain policy variables, for example, taxes or quotas. At the initial position some of these are chosen optimally and the remainder are fixed at predetermined positions - the vector describing the former group is $\omega$ and the latter group is $s$. Social welfare, $V(s, \omega)$, and excess demands, $E(s, \omega)$, are both functions of the vector $(s, \omega)$. The excess demands must be equal in general equilibrium to the net stocks (possibly zero) which are available. Note that in this general formulation welfare is entirely embodied in the function $V$ which fully encapsulates everything that is relevant for judgements. In contrast to the previous partial analysis we do not separate out the contributions of profit, government revenue and household welfare.

${ }^{2}$ The treatment here is based on $[6]$ and $[7]$. 
The choice of $s$ may then be described by the solution of the problem $(P)$ in Eq. (2.9) which is

Maximise over $s, V(s, \omega)$ subject to the constraint $E(s, \omega)=z$

We are supposing that the problem $(P)$ is feasible so that we shall usually require the dimension of $s$ to be greater than or equal to that of $E$ and $z$ (i.e. there are at least as many policy variables to be chosen as constraints). If the two dimensions are exactly equal, then, if the function $E$ is invertible, $s$ will be defined as a function of $z$ and there will be essentially no choice. Thus the special case (which we call fully determined) where policies are determined entirely by constraints is included. Further constraints, in addition to those arising through $E(s)=z$ may be added to the analysis, although they will add extra terms to the Lagrangian (see below). In the fully determined case we may regard $s$ as equilibrating variables which, together with the constraints $E(\quad)=z$, tell us how goods are allocated (e.g. through price adjustment or quota allocations). The assumption that there are at least as many policy variables as constraints is thus rather weak and simply tells us that the model provides a description of the allocation process.

The Lagrangian for $\mathrm{Eq} .(2.9)$ is

$$
L(s, \omega)=V(s, \omega)-\nu[E(s, \omega)-z]
$$

where $\nu$ is the set of shadow prices. The shadow price of a good is defined as the increase in the value of the social welfare function when an extra unit of public supplies is made available. It follows (as a deduction not a definition) that they will be equal to the Lagrange multipliers for $(P)$ if the $s$ are chosen optimally. Notice that the definition of the shadow prices also covers the case where the $s$ are determined entirely by the constraints. The first-order conditions for a maximum are

$$
\frac{\partial L}{\partial s}=0 \text { or } \frac{\partial V}{\partial s}-\nu \cdot \frac{\partial E}{\partial s}=0
$$

A reform is a change $d \omega$ in the policy variables $\omega$ which had previously been seen as pre-determined. In order to satisfy the scarcity constraints that excess demand be unchanged, we must have, from Eq. (2.9),

$$
\frac{\partial E}{\partial \omega} d \omega+\frac{\partial E}{\partial s} d s=0
$$

The consequent change in social welfare using Eqs. (2.11) and (2.12) is

$$
d V=\frac{\partial V}{\partial \omega} d \omega+\frac{\partial V}{\partial s} d s=\left(\frac{\partial V}{\partial \omega}-\nu \cdot \frac{\partial E}{\partial \omega}\right) d \omega \ldots
$$


Hence the net response of social welfare to a reform is given by the direct effect on social welfare $\frac{\partial V}{\partial \omega}$ less the cost of the extra net demands at shadow prices $\nu \frac{\partial E}{\partial \omega}$. Obviously the first-order condition for optimality of the policies $\omega$ is the equality of $\frac{\partial V}{\partial \omega}$ and $\nu \frac{\partial E}{\partial \omega}$. Equation (2.13) is the generalization of this more complex world of Eq. (2.8). Notice that it is a theory of reform for movements away from an initial position where the $s$ are set optimally. Again, however, we should stress that this includes the case where policy-makers are so constrained that no degrees of freedom for that choice are available. We can think of the maximum for problem $(P)$ as being a function of $\omega$ and $z$. This is used occasionally below and denoted by $W(\omega, z)$. From standard programming principles, $\partial W / \partial z$ is equal to $\nu$.

Let us suppose now that prices faced by producers are $p$ and by consumers are $q$, that $y(s, \omega)$ is the vector of net supplies (positive entries in $y$ are outputs and negative entries inputs) by producers and $x(s, \omega)$ is the vector of net demands by households (positive entries in $x$ are demands and negative entries supplies). We assume for the moment that intermediate goods are not taxed and return to this issue later. Then $E=x-y$ and

$$
-\nu \cdot E=\nu \cdot(y-x)=(\nu-p) \cdot y+(q-\nu) \cdot x+p \cdot y-q \cdot x \ldots \ldots
$$

But $p \cdot y-q \cdot x$ is the profits of firms less the expenditure of households and is therefore the direct tax revenue of the government. Hence we can write

$$
-\nu \cdot E=\begin{array}{llllllll}
R_{\nu} & \ldots & \ldots & \ldots & \ldots & \ldots & \ldots & \ldots
\end{array}
$$

where $R_{\nu}$ is the government revenue at shadow prices since we may interpret $(q-\nu)$ as 'shadow consumption taxes' and $(\nu-p)$ as 'shadow producer taxes' (so that $\nu y$ is 'shadow profit' and $p y$ actual profit). The change in welfare from the reform $d \omega$ is

$$
d V=\left(\frac{\partial V}{\partial \omega}+\frac{\partial R_{\nu}}{\partial \omega}\right) d \omega
$$

which is the direct increase in welfare $\frac{\partial V}{\partial \omega}$ plus the change in shadow revenue (encapsulating the changes in welfare arising from the required general-equilibrium adjustments to the changes in $\omega$ ).

Consider the special case where we make indirect tax changes $d t$ holding producer prices and any other variables affecting production constant so that any direct effect on $y$ is zero. The change in welfare is then, using either Eq. (2.13) or Eq. (2.16), 


$$
d V=\left(\frac{\partial V}{\partial t}-\nu \cdot \frac{\partial x}{\partial t}\right) d t
$$

The vector in brackets in Eq. (2.17) may be seen as the marginal social value of increasing the tax rate and represents the direct effect $\partial V / \partial t$ less the marginal cost of supplying the extra consumer demand $\nu \partial x / \partial t$. Notice that changing $t_{i}$ by itself and holding production constant is, of course, infeasible. But the role of the shadow price is precisely to take account of the change in welfare arising from the generalequilibrium consequences of restoring feasibility.

Eq. (2.17) may be rewritten, where consumer prices are $q$, as

$$
d V=\left[\frac{\partial V}{\partial t}+\frac{\partial}{\partial t}(q \cdot x)-p \cdot \frac{\partial x}{\partial t}+(p-\nu) \cdot \frac{\partial x}{\partial t}\right] d t \ldots
$$

since the direct effect of the change does not alter lump-sum consumer incomes, and thus $q \cdot x$ is a constant. Now, from Eq. (2.5), since we are holding $p$ constant, we may rewrite Eq. (2.18) as

$$
d V=\left[\frac{\partial V}{\partial t}+\frac{\partial}{\partial t}(t \cdot x)+(p-\nu) \cdot \frac{\partial x}{\partial t}\right] d t \quad \ldots \quad \ldots
$$

This generalizes the decomposition of Eq. (2.8) using Eqs. (2.2) and (2.3). The first term in Eq. (2.19) is the direct effect of the price increase on households, the second is the effect on tax revenue and the third is the difference between the market cost and shadow cost of meeting extra demands.

If producer prices are proportional to the shadow prices, i.e.

$$
\nu \quad=\lambda p
$$

again using Eq. (2.5) and the fact that $q \cdot x$ is a constant, the marginal social value is

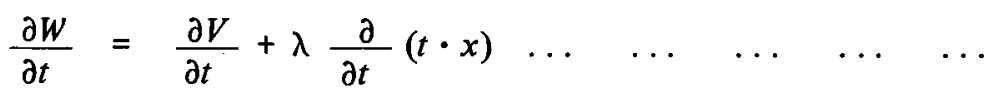

which corresponds to the special case of the partial-equilibrium version where one considers only $\Delta V$ and $\Delta R$. Thus $\lambda$ may be seen as the shadow value of government revenue.

An alternative and convenient way to express the issues which arise in this last case is using the statistic 


$$
\lambda_{i} \quad=-\begin{array}{llllllll}
\frac{\partial V}{\partial t_{i}} / \frac{\partial R}{\partial t_{i}} & \ldots & \ldots & \ldots & \ldots & \ldots & \ldots
\end{array}
$$

Then $\lambda_{i}$ is the marginal cost in terms of social welfare of an extra unit of government revenue. Thus if $\lambda_{i}<\lambda$, increasing the $i$ th tax imposes a social cost lower in value than the revenue raised (assuming $\frac{\partial R}{\partial t_{i}}$ is positive). If $\lambda_{i}<\lambda_{j}$, then one can increase social welfare at constant revenue by switching a unit of revenue on the margin from good $i$ to good $j$. We have employed the concept of $\lambda_{i}$ as the marginal cost of revenue extensively in our earlier works; see Ahmad and Stern, [1]; [2] ; [3] ; [4] and [5] for a full exposition.

Where $p$ is not proportional to $\nu$, we have the marginal social value in Eq. (2.21) replaced by

$$
\frac{\partial W}{\partial t}=\frac{\partial V}{\partial_{t}}+\lambda\left(\frac{\partial R}{\partial_{t}}+\frac{\partial S}{\partial_{t}}\right)
$$

where $\frac{\partial S}{\partial t_{i}}$ is $(p-\nu) \cdot \frac{\partial x}{\partial t_{i}}$ or the difference between the market cost of meeting extra demands and the shadow cost, and we have inserted $\lambda$ for comparability with Eq. (2.21). (This is simply a choice of units for $V$ and $\nu$.)

If we write

$$
\mu_{i} \quad=-\frac{\partial V}{\partial t_{i}} / \frac{\partial S}{\partial t_{i}}
$$

then an increase in the $i$ th tax will increase social welfare if

$$
\frac{1}{\lambda_{i}}+\frac{1}{\mu_{i}}>\frac{1}{\lambda}
$$

Hence the statistic $\lambda_{i}$ (or $1 / \lambda_{i}$ ) is an important element in the analysis when shadow prices are not proportional to producer prices. The number $1 / \lambda_{i}$ is the gain in government revenue from a unit decrease in social welfare arising from an increase in the tax $i$ and to it must be added the gain in shadow tax revenue associated with the difference between the market cost and shadow cost of meeting the changed demands. If the sum is greater than the cost $(1 / \lambda)$ of restoring the unit of welfare, then the tax should be increased. Similarly we buy a unit of welfare at cost $\left(1 / \lambda_{i}+1 / \mu_{i}\right)$ expressed in terms of government revenue from reducing the $i$ th tax; if this is less than the cost of $1 / \lambda$ then the tax should be reduced. Similarly if $\left(1 / \lambda_{i}+1 / \mu_{i}\right)<\left(1 / \lambda_{j}+1 / \mu_{j}\right)$ we can preserve equilibrium and increase welfare by switching taxation on the margin from $i$ to $j$. 
An alternative way to express the results in Eqs. (2.24) and (2.25) is to write

$$
\begin{array}{lllllllll}
\lambda_{i}^{\nu} & = & -\frac{\partial V}{\partial t_{i}} / \frac{\partial R_{\nu}}{\partial t_{i}} & \ldots & \ldots & \ldots & \ldots & \ldots & \ldots
\end{array}
$$

where $R_{\nu}$ is the shadow government revenue defined as the r.h.s. of Eq. (2.14). Then, from Eq. (2.16) we have a welfare-improving reform on switching a unit of shadow revenue on the margin from $i$ to $j$ if

$$
\begin{array}{llllllllll}
\lambda_{i}^{\nu}>\lambda_{j}^{\nu} & \ldots & \ldots & \ldots & \ldots & \ldots & \ldots & \ldots & \ldots
\end{array}
$$

Note that holding shadow revenue constant takes account of the full generalequilibrium constraints (just as holding actual revenue constant does for the case where producer and shadow prices coincide).

To calculate $\lambda_{i}$ we require $\frac{\partial V}{\partial t_{i}}$ and $\frac{\partial R}{\partial t_{i}}$. These are given (where there are $H$ hou seholds indexed $h=1,2, \ldots H$,) by

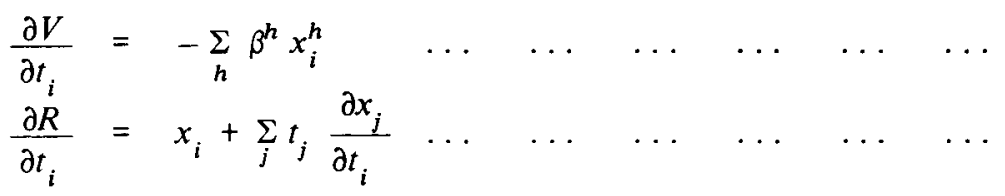

where $\beta^{h}$ is the social marginal utility of income for household $h$ (a value judgement), and $x_{i}^{h}$ is the demand by household $h$ for good $i$. Where intermediate goods are taxed Eqs. (2.28) and (2.29) remain valid but the taxes have to be interpreted as effective taxes where these can be defined (see Eq. 3.7 below). This is because we express final demands, $x$, as functions of the prices of final goods, which embody taxes on outputs, taxes on inputs, inputs into inputs and so on.

Eqs. (2.13), (2.17), (2.22) and (2.25) show, in decreasing order of generality, how the calculation of shadow prices and effective taxes may be embodied in an analysis of reform. Their application involves data on household expenditures and aggregate demand responses in addition to the shadow prices and will be the subject of our subsequent papers.

\section{EFFECTIVE TAXES}

\section{Theory}

In a world where there are many types of taxes, and their effects may be complex, one may wish to find simple ways of summarizing the tax system. One may, for example, wish to implement calculations of $\lambda_{i}$, such as those described in Eqs. (2.22), (2.28) and (2.29), or simply describe to a policy-maker some of the effects of tax policy which may not be obvious. We shall do this for indirect taxes 
by asking for each domestically produced good how much government revenue would increase if output went up by one unit. We call the answer to this question 'the effective tax'. We shall see that we can interpret the calculation of the effective tax as a decomposition of the market price of a good into a portion (the effective tax) going to the government and a portion which is payment to domestic factors and to foreigners. It is clear from the definition of the effective tax that we are referring to domestic production. Further, the answer to our question will depend on the conditions under which production takes place and the way in which prices are formed. We shall present this, using a simple input-output framework in a way which allows empirical application.

In a closed economy the standard input-output model yields prices in equilibrium with perfect competition and constant returns to scale

$$
p_{a^{\prime}}=p_{a^{\prime}} A+y^{\prime}
$$

where $p_{a}$ is the price vector, $A$ is the input-output matrix, $y$ the vector of per unit payments to factors and where there is no taxation. If all output is taxed at a per unit rate, then sellers receive $p_{a}-t$ where $t$ is the vector of taxes and $p_{a}$ is the purchaser price. Writing $p_{p}$ for the seller's price we have

$$
\begin{array}{llllllllll}
p_{p} & = & p_{a}-t & \ldots & \ldots & \ldots & \ldots & \ldots & \ldots & \ldots
\end{array}
$$

We use the subscripts $a$ and $p$ to remind us that we are thinking of prices, $p_{a}$, paid by someone who acquires goods, being different from those, $p_{p}$, received by the producers. In equilibrium

$$
p_{p^{\prime}}=p_{a^{\prime} A}+y^{\prime}
$$

Adding $t$ to both sides and using Eq. (3.2) we have

$$
p_{a^{\prime}}=t^{\prime}(I-A)^{-1}+y^{\prime}(I-A)^{-1}
$$

In this model, $t^{\prime}(I-A)^{-1}$ is 'the effective tax' and $y^{\prime}(I-A)^{-1}$ the 'basic price'. More generally the basic price corresponds to $t=0$.

Suppose now that the economy is open and that domestic production requires imported inputs. To keep things simple we shall assume that imported inputs are distinct from domestic inputs and may be imported freely at pre-tax or c.i.f. prices of $p_{m}$. Then in equilibrium we have

$$
p_{p^{\prime}} \quad=\quad p_{a^{\prime}} A_{d}+\left(p_{m^{\prime}+} t_{m^{\prime}}\right) A_{m}+y^{\prime} \quad \ldots \quad \ldots \quad \ldots \quad \ldots
$$


where $A_{d}$ is the matrix of domestic inputs per unit of domestic output, $A_{m}$ is the matrix of foreign inputs per unit of domestic output and $t_{m}$ is the vector of per unit taxes or tariffs on imported goods. Then we have

$$
\begin{aligned}
& p_{a^{\prime}}=t_{d^{\prime}}\left(I-A_{d}\right)^{-1}+t_{m} \cdot A_{m}\left(I-A_{d}\right)^{-1}+p_{m} \cdot A_{m}\left(I-A_{d}\right)^{-1} \\
& +y^{\prime}\left(I-A_{d}\right)^{-1} \quad \ldots \quad \ldots \quad \ldots \quad \ldots \quad \ldots \quad \ldots \quad \ldots
\end{aligned}
$$

where we write domestic per unit taxes as the vector $t_{d}$. In this case the effective $\operatorname{tax}$ is

$$
t_{e^{\prime}}=t_{d} \cdot\left(I-A_{d}\right)^{-1}+t_{m} \cdot A_{m}\left(I-A_{d}\right)^{-1} \quad \ldots \quad \ldots \ldots
$$

The element of foreign exchange in the price is $p_{m}, A_{m}\left(I-A_{d}\right)^{-1}$ and the element of domestic factor payments is $y^{\prime}\left(I-A_{d}\right)^{-1}$. The results of calculations of the expression for $t_{e^{\prime}}$ in Eq. (3.7) are presented later.

There are a number of features of the model we have presented which should be noted here. The equilibrium condition, Eq. (3.5), the decomposition of market price, Eq. (3.6), and the expression for $t_{e}$ in Eq. (3.7) as the additional government revenue from an extra unit of output, arise from the assumptions of perfect competition and constant returns to scale together with 'non-competitive' imports for inputs. Under these assumptions, the equilibrium condition applies whatever one assumes about demand, the number and elasticities of factors in supply, and their relative prices and substitutability in production. However, without a single factor, or fixed relative prices of factors (and we include foreign exchange here) we cannot interpret Eq. (3.5) as giving the effect of tax increases on market price: see Ahmad and Stern, [4] for further discussion of this point. In particular note that were a good to be imported freely and compete with a domestically produced good in output markets then its market price would be fixed and Eq. (3.6) would be describing the effects of taxes on factor payments.

The model used in this section is equivalent to the full forward shifting of taxes. While the shifting of taxes in a given context is closely related to market structure $[16 ; 18]$, full forward shifting may be seen as a reasonable description of a central case - there may be cases with more than 100 percent shifting and others with less. For empirical observations from Pakistan see Radhu [14], Irfan [8], Naqvi [10] and Jeetun [9].

We have implicitly been ignoring income tax in our discussion of the effective tax. Thus the effective tax here is the change in indirect tax revenue arising from the output change. 
Finally, up to this point we have not taken into account the taxation of goods which arises through the capital stocks required in their production. In a steady-state model the analysis of Eqs. (3.5) - (3.7) can be modified in a straightforward way by replacing $A_{d}$ by $\left(A_{d}+r B_{d}\right)$ and $A_{m}$ by $\left(A_{m}+r B_{m}\right)$ where $B_{d}$ is the matrix of stocks of domestic goods required as capital for the production of domestic goods, $B_{m}$ the matrix of stocks of imported capital goods for domestic production, and $r$ a real rate of interest. The steady-state assumption is necessary since otherwise be have to consider carefully the time pattern of accumulation, taxes and rates of interest in the determination of prices. Whilst it is unsatisfactory in some respects, it is the simplest way of introducing capital into the analysis.

\section{Data}

Major data requirements include information on revenue collections for the major indirect taxes calssified by commodities, and tables of input-output coefficients for absorptions of domestic and imported goods and services.

Federal revised tax collections for the year $1975-76$ have been obtained mainly from [13]. The major domestic tax is the excise duty, which realized a gross revenue of Rs 4,596 million. Commodity-wise realizations taken from [13] were mapped to an 87-good classification chosen to match a revised input-output table for 1975-76. Of the total excise revenue, Rs 1,742 million was collected as a result of ad valorem excise taxes on certain commodities. However, since a breakdown of total collection according to commodities is available, it is easy to convert the total revenue collection into a specific excise equivalent. The nominal, or implicit, tax rate derived has a number of advantages. Firstly, since we deal with actual collections, this circumvents the problem of evasion associated with the use of announced statutory rates. Moreover, there may be a multiplicity of announced tax rates for the commodities at the level of aggregation of most input-output tables. Actual collections thus provide a weighted average of the implicit tax rates for any given commodity group. The commodity collections of revenue for each of the major indirect taxes are presented in Appendix Table 1. Some excisable goods are also subject to a sales tax, which applies to imports as well as to domestically produced goods. Of the total revenue collection of Rs 300 million from the sales tax on domestic goods, we have been able to allocate Rs 245 million to the 87 -commodity groups (the remaining Rs 55 million are not included in this calculation). The revenue breakdowns by commodity allocations are also presented in Appendix Table 1. In addition there were, in $1975-76$, production surcharges on specific locally produced goods. We have used the Budget estimates of Rs 805 million and allocations for petroleum, natural gas and fertilizers.

The major federal government subsidies have been allocated to the imported and domestically produced goods according to the 87 -commodity classification. The 
largest subsidy was on wheat, Rs 961 million being incurred on imported wheat and Rs 222 million on domestic production. These subsidies form part of the current expenditures. There was also a subsidy of Rs 26.48 million on wheat seeds shown under Non-Development Capital Expenditure. The other major subsidy is on fertilizers, which is treated as a development expenditure in the government accounts. Expenditures on plant protection have not been allocated. We have not included provincial government subsidies. In addition, losses of public sector enterprises may be treated as implicit subsidies. We have not, at this stage, made an attempt to incorporate these into our analysis.

The rate implicit in the revenue collections is treated as an average for the sector concerned. To the extent that the revenue collections are net of refunds, particularly in the case of sales tax, the implicit rate will not overstate the tax attributable to a commodity. Another advantage of using revenue collections is that these incorporate the result of the tax collection effort, given administrative considerations and evasion, in a way that announced or statutory rates do not. However, it is important to keep in mind the level of aggregation of the analysis dictated by the classification of the input-output table. For very detailed sectoral analysis, one would in principle use estimates from the more aggregative analysis as an input into the sectoral work.

Of the main trade taxes, export duties do not affect the calculation of effective taxes, since exports are assumed not to enter into the domestic production circuit (they are omitted from Appendix Table 1). ${ }^{3}$ Revenue collections from exports are shown in Appendix Table 2. On imported goods, the main taxes are import duties and sales taxes. The import duties realized a sum of Rs 4430 million in 1975-76. Of this, we have been able to allocate all except Rs 600 million to our commodity groups. The 'missing' import tax collection might bias our implicit import duties downwards for some commodity groups. The sales tax on the imports yielded a revenue of Rs 850 million in 1975-76. Again, we have only been able to allocate Rs 700 million of this revenue to our commodity groups. The commodity-wise allocations for import duties and sales taxes on imports are also presented in Appendix Table 1.

The input-output matrix used in this paper is a revised version of the PIDE table for 1975-76 [15] - a 118-sector matrix of domestic and imported flows at purchaser prices. Thus we have estimates for both imported and domestic coefficient matrices, $A_{m}$ and $A_{d}$. The 118-sector input-output table has been merged to 87 sectors. This reclassification has been governed, as mentioned above, by a need to match as closely as possible the tax revenue categories and input-output sectors. The reclassification has had an effect in terms of the groups of commodities that could be

${ }^{3}$ Implicitly we are assuming that taxes are fully shifted onto exports which may be unsatisfactory. There may also be some effect on domestic factor incomes. 
classified into tradables and non-tradables, an issue which arises in the calculation of shadow prices.

The final data set required is an estimate of a capital stock matrix, $B$. From the data available to us $[11 ; 12]$ we have been able to put together an estimate for under some admittedly crude assumptions. Assuming that all assets depreciate at 10 percent per year and that the current investment is entirely used for replacement, using a 10 percent rate of interest for $r$ implies that $r B$ is equal to current investment. This total proxy for assets is allocated to the investment-goods sectors under proportions given in [11]. The resulting matrix is, in turn, divided into assets which are imported and those which have been domestically produced, using the proportions of the absorption of imports and domestic goods in 1975-76. We thus have $r B_{d}$ and $r B_{m}$, representing stocks of domestic and imported assets. ${ }^{4}$

\section{The Effective-Tax Calculations}

The effective-tax estimates for 1975-76 may be decomposed into the component domestic and imported sources as shown in Eq. (3.7), where the first element on the RHS is the effective tax arising from domestic sources, say $t_{e(d)}$, and the second element represents the effective tax arising from inputs of imported goods, $t_{e(m)}$, into domestic production. These are modified when we take into account the tax element in price attributable to the taxation of fixed assets, given our estimates for $B_{d}$ and $B_{m}$ and nominal taxes $t_{d}$, and $t_{m}$. The resulting components of effective taxes, including this last effect, are

and

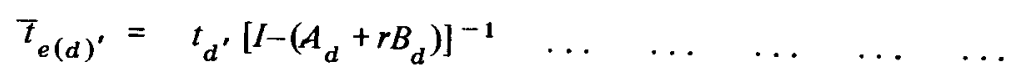

$$
\bar{t}_{e(m)^{\prime}}=t_{m} \cdot\left(A_{m}+r B_{m}\right)\left[\begin{array}{lllll} 
& \left.\left(A_{d}+r B_{d}\right)\right]^{-1} & \ldots & \ldots & \ldots
\end{array}\right.
$$

where $\bar{t}_{e(d)}$ and $\bar{t}_{e(m)}$ are the effective taxes on domestic goods and imports into domestic production respectively. The total effective tax including the effects arising
from assets is

$$
\bar{t}_{e}=\bar{t}_{(d)}+\bar{t}_{e(m)}
$$

In Table 1 we present an estimate of that part of the effective tax, $t_{e(m)}$ and $\bar{t}_{e(m)}$, which arises from the taxation of imported inputs into domestic production. The taxes included in the estimation of $t_{m}$ in Eq. (3.9) are the import duty, the sales tax and the subsidy on imported wheat discussed above. As is evident from the table, all domestic commodities are affected by the taxation of inputs, although the effect on agricultural products is quite small - in most cases well under one

${ }^{4}$ These could be made available upon request. 
Table 1

Effective Taxes on Imports into Domestic Production

\begin{tabular}{|c|c|c|c|}
\hline & Goods and Service & $t_{e(m)}$ & $\bar{t}_{e(m)}$ \\
\hline 1 & Wheat & 0.0038 & 0.0078 \\
\hline 2 & Rice & 0.0084 & 0.0137 \\
\hline 3 & Cotton & 0.0034 & 0.0079 \\
\hline 4 & Sugar-cane & 0.0023 & 0.0063 \\
\hline 5 & Tobacco Growing & 0.0020 & 0.0051 \\
\hline 6 & Oilseeds & 0.0020 & 0.0057 \\
\hline 7 & Pulses & 0.0061 & 0.0118 \\
\hline 8 & Other Crops & 0.0024 & 0.0046 \\
\hline 9 & Livestock & 0.0025 & 0.0054 \\
\hline 10 & Fishing & 0.0027 & 0.0042 \\
\hline 11 & Forestry & 0.0017 & 0.0039 \\
\hline 12 & Mining \& Quarrying & 0.0097 & 0.0148 \\
\hline 13 & Grain Milling & -0.0503 & -0.0413 \\
\hline 14 & Rice Milling \& Husking & 0.0137 & 0.0259 \\
\hline 15 & Edible Oils & 0.0086 & 0.0200 \\
\hline 16 & Sugar Refining & 0.0028 & 0.0110 \\
\hline 17 & Gur and Khandsari & 0.0026 & 0.0099 \\
\hline 18 & Tea Blending & 0.0239 & 0.0332 \\
\hline 19 & Fish \& Preparations & 0.0076 & 0.0144 \\
\hline 20 & Confectionery \& Bakery & 0.0103 & 0.0209 \\
\hline 21 & Other Food Industries & 0.0064 & 0.0180 \\
\hline 22 & Beverages & 0.0246 & 0.0339 \\
\hline 23 & Cigs. \& Tobacco Products (LS) & 0.0056 & 0.0124 \\
\hline 24 & Bidis (i.e. Tobacco-SS) & 0.0070 & 0.0109 \\
\hline 25 & Cotton Yarn & 0.0227 & 0.0370 \\
\hline 26 & Cotton Ginning & 0.0049 & 0.0150 \\
\hline 27 & Cotton Textiles (LS) & 0.0204 & 0.0357 \\
\hline 28 & Cotton Textiles (SS) & 0.0145 & 0.0254 \\
\hline 29 & Silk \& Synthetic Textiles & 0.0522 & 0.0613 \\
\hline 30 & Woollen Textiles \& Hosiery & 0.0317 & 0.0451 \\
\hline 31 & Threadballs \& Other Textiles & 0.0183 & 0.0365 \\
\hline 32 & Carpets \& Rugs & 0.0433 & 0.0530 \\
\hline 33 & Made-up Garments & 0.1182 & 0.1283 \\
\hline 34 & Footwear (non-rubber) & 0.0238 & 0.0326 \\
\hline 35 & Wood, Cork \& Furniture & 0.0095 & 0.0210 \\
\hline
\end{tabular}


Table $1-($ Continued $)$

\begin{tabular}{llll}
\hline Goods and Services & $t_{e(m)}$ & $\bar{t}_{e(m)}$ \\
\hline 36 & Paper \& Products & 0.0096 & 0.0261 \\
37 & Printing \& Publishing & 0.0186 & 0.0317 \\
38 & Leather \& Products & 0.0059 & 0.0123 \\
39 & Rubber Footwear & 0.0847 & 0.0923 \\
40 & Rubber Products & 0.0296 & 0.0415 \\
41 & Pharmaceuticals & 0.1276 & 0.1379 \\
42 & Fertilizer & 0.0146 & 0.0364 \\
43 & Perfumes \& Cosmetics & 0.0493 & 0.0596 \\
44 & Paints \& Varnishes & 0.0612 & 0.0735 \\
45 & Soaps \& Detergents & 0.0099 & 0.0208 \\
46 & Chemicals & 0.0155 & 0.0335 \\
47 & Plastic Products & 0.0127 & 0.0265 \\
48 & Petroleum Products & 0.0218 & 0.0298 \\
49 & Cement & 0.0157 & 0.0460 \\
50 & Glass \& Products & 0.0726 & 0.0939 \\
51 & Non-Metallic Mineral Products & 0.0166 & 0.0291 \\
52 & Basic Metals & 0.0339 & 0.0519 \\
53 & Metal Products & 0.0544 & 0.0640 \\
54 & Iron \& Steel Remg & 0.0085 & 0.0135 \\
55 & Agricultural Machinery & 0.0878 & 0.0981 \\
56 & Other Non-Electrical Machinery & 0.0406 & 0.0556 \\
57 & Electrical Machinery & 0.0702 & 0.0817 \\
58 & Bicycles & 0.0368 & 0.0512 \\
59 & Transport (large-scale) & 0.0820 & 0.0940 \\
60 & Ship Building & 0.0402 & 0.0498 \\
61 & Transport Equipment (small-scale) & 0.0090 & 0.0211 \\
62 & Office Equipment & 0.0707 & 0.0823 \\
63 & Sports Goods & 0.0425 & 0.0507 \\
64 & Surgical Instruments & 0.0153 & 0.0249 \\
65 & Other Large-scale Manufacturing & 0.0140 & 0.0264 \\
66 & Other Small-scale Manufacturing & 0.0310 & 0.0415 \\
67 & Low-cost Residential Buildings & 0.0145 & 0.0236 \\
68 & Luxurious Residential Buildings & 0.0285 & 0.0377 \\
69 & Rural Buildings & 0.0101 \\
70 & Factory Buildings & 0.0434 \\
71 & Public Buildings & 0.0405 \\
72 & Roads & 0.0072 \\
73 & Infrastructure & 0.0630 \\
\hline & & $C o n t i n e$ \\
\hline
\end{tabular}




\begin{tabular}{llll}
\hline 74 & Ownership of Dwellings & 0.0024 & 0.0122 \\
75 & Electricity & 0.0040 & 0.0854 \\
76 & Gas & 0.0024 & 0.0796 \\
77 & Wholesale \& Retail Trade & 0.0010 & 0.0066 \\
78 Road Transport & 0.0472 & 0.0512 \\
79 & Rail Transport & 0.0167 & 0.0383 \\
80 & Air Transport & 0.0183 & 0.0243 \\
81 & Water Transport & 0.0059 & 0.0094 \\
82 & Television & 0.0392 & 0.0459 \\
83 & Radio & 0.0107 & 0.0178 \\
84 & Phone, Telegraph \& Post & 0.0049 & 0.0188 \\
85 & Banking \& Insurance & 0.0081 & 0.0145 \\
86 & Government & 0.0049 & 0.0229 \\
87 Services & 0.0012 & 0.0069
\end{tabular}

$$
\begin{array}{ll}
\text { Notes: } & \text { 1. } t_{e(m)^{\prime}}=t_{m} A_{m}\left(I-A_{d}\right)^{-1} \\
& \text { 2. } \bar{t}_{e(m)^{\prime}}=t_{m^{\prime}}\left(A_{m}+r B_{m}\right)\left[I-\left(A_{d}+r B_{d}\right)\right]^{-1} \\
& \text { where } t_{m} \text { includes import duties, sales taxes and subsidies on imported goods. }
\end{array}
$$

percent of the purchaser price. Note, however, that on manufactured good items the effective tax is higher, $1-3$ percent. There is an effective subsidy of 5 percent on 'grain milling', which is reduced to 4 percent if the taxation of imported capital stock is taken into account. Other consumer items, such as textiles, display a much higher effective import tax, generally between 3 percent and 5 percent, (with 'rubber footwear' at 9 percent). The production of domestic intermediate goods and durable items shows a yet higher effective import duty in the 5 percent -10 percent range. Pharmaceuticals have the highest effective import duty at 13 percent. The taxation from imported capital goods $\left(t_{e(m)}-t_{e(m)}\right)$ adds less than 2 percent to the purchaser price of most items - some exceptions are 'perfumes and cosmetics' ( 3 percent), and 'gas' ( 8 percent). However this forms a significant proportion of the value of $\bar{t}_{e(m)}$ for most goods; and between 50 percent -60 percent for the agricultural sector, 66 percent for 'cement' and over 95 percent for 'electricity' and 'gas'.

The taxation arising through intermediate domestic inputs is also important (Table 2) and this is measured by the divergence $\bar{t}_{\text {diff (d) }}$ between the 'domestic' effective $\operatorname{tax} \bar{t}_{e(d)}$ and the nominal tax on domestic production, $t_{n o m(d)}$. Whilst this is less than one percent for agricultural commodities (1) - (8), it represents around 5 percent of the purchaser price of manufactured food items, beverages and tobacco. For most textile items, $\bar{t}_{\text {diff (d) }}$ is between 3 percent and 5 percent, and is generally higher for intermediate goods and durables at between 5 percent and 10 percent. In the case of 'electricity', which had no nominal tax in 1975-76, the 
domestic effective tax was as much as 13 percent of the purchaser prices, $\bar{t}_{\text {diff(d) }}$ coinciding with $\bar{t}_{e(d)}$ in this case.

Table 2

Effective Taxes from Domestic Goods and Services

\begin{tabular}{|c|c|c|c|c|}
\hline & Goods and Services & $t_{e(d)}$ & $\bar{t}_{e(d)}$ & $\bar{t}_{d i f f}$ \\
\hline 1 & Wheat & -0.0217 & -0.0214 & -0.0013 \\
\hline 2 & Rice & 0.0085 & 0.0096 & 0.0096 \\
\hline 3 & Cotton & 0.0014 & 0.0020 & 0.0020 \\
\hline 4 & Sugar-cane & 0.0027 & 0.0031 & 0.0031 \\
\hline 5 & Tobacco Growing & 0.1934 & 0.1933 & 0.0052 \\
\hline 6 & Oilseeds & 0.0043 & 0.0043 & 0.0043 \\
\hline 7 & Pulses & 0.0083 & 0.0086 & 0.0086 \\
\hline 8 & Other Crops & 0.0016 & 0.0025 & 0.0025 \\
\hline 9 & Livestock & 0.0001 & -0.0003 & 0.0003 \\
\hline 10 & Fishing & 0.0054 & 0.0063 & 0.0063 \\
\hline 11 & Forestry & 0.0023 & 0.0041 & 0.0041 \\
\hline 12 & Mining \& Quarrying & 0.0271 & 0.0294 & 0.0165 \\
\hline 13 & Grain Milling & -0.0106 & -0.0067 & -0.0067 \\
\hline 14 & Rice Milling \& Husking & 0.0128 & 0.0188 & 0.0188 \\
\hline 15 & Edible Oils & 0.1142 & 0.1187 & 0.0264 \\
\hline 16 & Sugar Refining & 0.2721 & 0.2761 & 0.0080 \\
\hline 17 & Gur and Khandsari & 0.0029 & 0.0061 & 0.0061 \\
\hline 18 & Tea Blending & 0.0774 & 0.0792 & 0.0097 \\
\hline 19 & Fish \& Preparations & 0.0071 & 0.0112 & 0.0112 \\
\hline 20 & Confectionery \& Bakery & 0.1590 & 0.1644 & 0.0593 \\
\hline 21 & Other Food Industries & 0.0205 & 0.0250 & 0.0224 \\
\hline 22 & Beverages & 0.1273 & 0.1325 & 0.0566 \\
\hline 23 & Cigs. \& Tobacco Products (LS) & 0.7613 & 0.7649 & 0.0445 \\
\hline 24 & Bidis (i.e. Tobacco-SS) & 0.0523 & 0.0542 & 0.0542 \\
\hline 25 & Cotton Yarn & 0.0424 & 0.0498 & 0.0218 \\
\hline 26 & Cotton Ginning & 0.0050 & 0.0092 & 0.0092 \\
\hline 27 & Cotton Textiles (LS) & 0.0509 & 0.0592 & 0.0370 \\
\hline 28 & Cotton Textiles (SS) & 0.0283 & 0.0343 & 0.0343 \\
\hline 29 & Silk \& Synthetic Textiles & 0.1273 & 0.1330 & 0.0537 \\
\hline 30 & Woollen Textiles \& Hosiery & 0.1057 & 0.1116 & 0.0285 \\
\hline 31 & Threadballs \& Other Textiles & 0.0353 & 0.0425 & 0.0425 \\
\hline 32 & Carpets \& Rugs & 0.0332 & 0.0382 & 0.0382 \\
\hline
\end{tabular}


Table $2-($ Continued $)$

\begin{tabular}{llrrr}
\hline 33 & Made-up Garments & 0.0148 & 0.0205 & 0.0205 \\
34 & Footwear (non-rubber) & 0.0362 & 0.0407 & 0.0264 \\
35 & Wood, Cork \& Furniture & 0.0245 & 0.0286 & 0.0286 \\
36 & Paper \& Products & 0.1163 & 0.1231 & 0.0587 \\
37 & Printing \& Publishing & 0.0419 & 0.0482 & 0.0482 \\
38 & Leather \& Products & 0.0174 & 0.0197 & 0.0090 \\
39 & Rubber Footwear & 0.0101 & 0.0145 & 0.0145 \\
40 & Rubber Products & 0.3341 & 0.3375 & 0.0273 \\
41 & Pharmaceuticals & 0.0268 & 0.0309 & 0.0309 \\
42 & Fertilizer & -0.1992 & -0.1884 & 0.0787 \\
43 & Perfumes \& Cosmetics & 0.3894 & 0.3934 & 0.0492 \\
44 & Paints \& Varnishes & 0.3239 & 0.3266 & 0.0389 \\
45 & Soaps \& Detergents & 0.1605 & 0.1661 & 0.0452 \\
46 & Chemicals & 0.0972 & 0.1041 & 0.0515 \\
47 & Plastic Products & 0.3689 & 0.3717 & 0.0815 \\
48 Petroleum Products & 0.3188 & 0.3207 & 0.0092 \\
49 & Cement & 0.2066 & 0.2250 & 0.1045 \\
50 & Glass \& Products & 0.2964 & 0.3056 & 0.0989 \\
51 & Non-Met. Mineral Products & 0.0607 & 0.0670 & 0.0632 \\
52 & Basic Metals & 0.0183 & 0.0243 & 0.0243 \\
53 & Metal Products & 0.0852 & 0.0880 & 0.0150 \\
54 & Iron \& Steel Remg & 0.0183 & 0.0214 & 0.0214 \\
55 & Agricultural Machinery & -0.0713 & -0.0692 & 0.0092 \\
56 & Other Non-Electrical Machinery & 0.0235 & 0.0269 & 0.0269 \\
57 & Electrical Machinery & 0.0120 & 0.0143 & 0.0143 \\
58 & Bicycles & 0.0433 & 0.0487 & 0.0487 \\
59 & Transports large-scale & 0.0160 & 0.0186 & 0.0153 \\
60 & Ship Building & 0.0122 & 0.0156 & 0.0156 \\
61 & Transport Equipment small-scale & 0.0146 & 0.0202 & 0.0202 \\
62 & Office Equipment & 0.0140 & 0.0168 & 0.0168 \\
63 & Sports Goods & 0.0120 & 0.0162 & 0.0162 \\
64 & Surgical Instruments & 0.0253 & 0.0296 & 0.0296 \\
65 & Other Large-scale Mfg & 0.5041 & 0.5073 & 0.0364 \\
66 & Other Small-scale Mfg & 0.0496 & 0.0538 & 0.0538 \\
67 & Low-cost Resid. Bldgs & 0.0519 & 0.0572 & 0.0572 \\
68 Luxurious Resid. Bldgs & 0.0523 & 0.0577 & 0.0577 \\
69 & Rural Buildings & 0.0241 & 0.0271 & 0.0271 \\
70 & Factory Buildings & 0.0542 & 0.0594 & 0.0594 \\
71 & Public Buildings & 0.0320 & 0.0358 & 0.0358 \\
\hline & & & $C 0 n t 7$ \\
\hline
\end{tabular}


Table $2-($ Continued $)$

\begin{tabular}{|c|c|c|c|c|}
\hline & Goods and Services & $t_{e(d)}$ & $\bar{t}_{e(d)}$ & $\bar{t}_{d i f f}$ \\
\hline 72 & Roads & 0.0194 & 0.0215 & 0.0215 \\
\hline 73 & Infrastructure & 0.0425 & 0.0631 & 0.0631 \\
\hline 74 & Ownership of Dwellings & 0.0108 & 0.0226 & 0.0226 \\
\hline 75 & Electricity & 0.0775 & 0.1306 & 0.1306 \\
\hline 76 & Gas & 0.4134 & 0.4641 & 0.0618 \\
\hline 77 & Wholesale \& Retail Trade & 0.0019 & 0.0055 & 0.0055 \\
\hline 78 & Road Transport & 0.0296 & 0.0323 & 0.0323 \\
\hline 79 & Rail Transport & 0.0581 & 0.0725 & 0.0725 \\
\hline 80 & Air Transport & 0.0692 & 0.0730 & 0.0730 \\
\hline 81 & Water Transport & 0.0020 & 0.0043 & 0.0043 \\
\hline 82 & Television & 0.0204 & 0.0240 & 0.0240 \\
\hline 83 & Radio & 0.0116 & 0.0164 & 0.0164 \\
\hline 84 & Phone, Telegraph \& Post & 0.0055 & 0.0157 & 0.0157 \\
\hline 85 & Banking \& Insurance & 0.0254 & 0.0293 & 0.0268 \\
\hline 86 & Government & 0.0092 & 0.0227 & 0.0227 \\
\hline 87 & Services & 0.0045 & 0.0089 & 0.0058 \\
\hline
\end{tabular}
Note: $\quad t_{e(d)}=t_{d},\left(I-A_{d}\right)^{-1}$$$
\bar{t}_{e(d)}=t_{d} \cdot\left[I-\left(A_{d}+r B_{d}\right)\right]^{-1}
$$$$
\bar{t}_{\text {diff }}=t_{e(d)}-t_{n o m}
$$
where $t_{\text {nom }}$ includes excises, surcharges, sales taxes on domestically produced goods and services.

The overall effective tax, from both domestic and imported sources, is given in Table 3. In Column 1 we present the nominal tax on domestic production, $t_{n o m}$. The effective taxes with and without the effects of the capital stock matrix, $t_{e}$, and $\bar{t}_{e}$, are given in Columns 3 and 2 respectively. As in the previous cases, all commodity groups are affected by the structure of indirect taxes, even though only 35 out of the total 87 domestic commodity groups are actually subject to nominal tax. In some cases the effective tax is quite high, as for 'tobacco products' for which the tax element in the purchaser price is around 78 percent. However, high effective taxes may reflect high nominal taxes. As before, it is the difference between effective and nominal taxes, $\bar{t}_{\text {diff }}$, which reflects the taxation of other commodities and assets, and may be thought of as a possible unintended consequence of government policy. In the case of 'tobacco products', $\bar{t}_{d i f f}$ is actually only 5.7 percent and nominal tax accounts for the bulk of the high effective tax. In general, for 
Table 3

Total Effective Taxes: $1975-76$

\begin{tabular}{|c|c|c|c|c|c|c|}
\hline & Goods and Services & $t_{\text {nom }}$ & $t_{e}$ & $\bar{t}_{e}$ & $\bar{t}_{d i f f}$ & $\bar{t}_{e}-t_{e}$ \\
\hline 1 & Wheat & -0. & -0.0179 & -0.0136 & 65 & 0.0043 \\
\hline 2 & Rice & 0.0000 & 0.0168 & 0.0233 & & 0.0065 \\
\hline 3 & Cotton & 0.0000 & 0.0 & 0.0 & & 0.0051 \\
\hline 4 & Sugar- & 0.0000 & 0.0050 & 0.0094 & 0.0094 & 0.0044 \\
\hline 5 & Tob & 0.1882 & 0.1953 & 0.1984 & 0.0103 & 0.0031 \\
\hline 6 & Oilseeds & 0.0000 & 0.00 & 0.0100 & 0.0 & 0.0036 \\
\hline 7 & Pulses & 0.0000 & 0.0 & 0.0205 & 05 & 0.0060 \\
\hline 8 & Other & 0.00 & 0.0 & 0.0071 & & 0.0031 \\
\hline 9 & Livest & 0.0000 & 0.00 & 0.0052 & 52 & 0.0026 \\
\hline 10 & Fishin & 0.0000 & 0.0 & 0.0106 & & 0.0025 \\
\hline 11 & Forestry & 0.0000 & 0.0040 & 0.0080 & 0.0080 & 0.0040 \\
\hline 12 & Mining & 0.0129 & 0.0367 & 0.0442 & 14 & 0.0075 \\
\hline 13 & Grain Milling & 0.0000 & -0.0609 & -0.0480 & -0.0480 & 0.0129 \\
\hline 14 & Rice Milling \& & 0.0000 & 0.0265 & 0.0448 & 0.0448 & 0.0183 \\
\hline 15 & Edible & 0.0923 & 0.1228 & 0.1388 & 0.0465 & 0.0160 \\
\hline 16 & Sugar $F$ & 0.2681 & 0.2 & 0.2871 & & 0.0122 \\
\hline 17 & Gur & 0.0 & 0.0 & 0.0159 & & 0.0105 \\
\hline 18 & Tea $\mathrm{B}$ & 0.0 & 0.1 & 0.1 & 8 & 0.0110 \\
\hline 19 & Fish & 0.0 & 0.0 & 0.0 & & 0.0109 \\
\hline 20 & Confection & 0.10 & 0.1693 & 0.1854 & & 0.0160 \\
\hline 21 & Other $\mathbf{F}$ & 0.0 & 0.0 & 0.0430 & & 0.0160 \\
\hline 22 & Beverages & 0.07 & 0.1 & 0.1665 & 0.0906 & 0.0146 \\
\hline 23 & Cigs. & 0.7204 & 0.7 & 0.7 & 69 & 0.0104 \\
\hline 24 & Bidis (i.e. Tobacco-SS) & 0.0000 & 0.0593 & 0.0652 & 0.0652 & 0.0059 \\
\hline 25 & Cotton Yarn & 0.02 & 0.0 & 0.0868 & 38 & 0.0217 \\
\hline 26 & Cotton Ginning & 0.0000 & 0.0 & 0.0241 & & 0.0143 \\
\hline 27 & Cotton $\mathrm{T}$ & 0.0222 & 0.0 & 0.0949 & & 0.0235 \\
\hline 28 & Cotton Text. & 0.0000 & 0.0427 & 0.0596 & 0.0596 & 0.0169 \\
\hline 29 & Silk \& Synthetic Text. & 0.0793 & 0.1795 & 0.1943 & 0.1150 & 0.0148 \\
\hline 30 & Woollen Text. \& Hosiery & 0.0831 & 0.1374 & 0.1567 & 0.0736 & 0.0193 \\
\hline 31 & Threadballs \& Other Text & 0.0000 & 0.0536 & 0.0790 & 0.0790 & 0.0254 \\
\hline 32 & Carpets \& Rugs & & 0.0764 & 0.0912 & 0.0912 & 0.0147 \\
\hline 33 & Made-up Garments & 0.0000 & 0.1330 & 0.1487 & 0.1487 & 0.0157 \\
\hline 34 & Footwear (non-rubber) & 0.0143 & 0.0601 & 0.0733 & 0.0590 & 0.0132 \\
\hline
\end{tabular}


Table $3-($ Continued $)$

\begin{tabular}{|c|c|c|c|c|c|c|}
\hline & Goods and Services & $t_{\text {nom }}$ & $t_{e}$ & $\bar{t}_{e}$ & $\bar{t}_{\text {diff }}$ & $T_{e}-t_{e}$ \\
\hline 35 & Wood, Cork \& Furniture & 0.0000 & 0.0340 & 0.0496 & 0.0496 & 0.0156 \\
\hline 36 & Paper \& Products & 0.0644 & 0.1259 & 0.1492 & 0.0848 & 0.0233 \\
\hline 37 & Printing \& Publishing & 0.0000 & 0.0605 & 0.0799 & 0.0799 & 0.0194 \\
\hline 38 & Leather \& Products & 0.0107 & 0.0233 & 0.0319 & 0.0213 & 0.0087 \\
\hline 39 & Rubber Footwear & 0.0000 & 0.0948 & 0.1068 & 0.1068 & 0.0120 \\
\hline 40 & Rubber Products & 0.3102 & 0.3637 & 0.3789 & 0.0687 & 0.0152 \\
\hline 41 & Pharmaceuticals & 0.0000 & 0.1544 & 0.1688 & 0.1688 & 0.0144 \\
\hline 42 & Fertilizer & -0.2670 & -0.1846 & -0.1519 & 0.1151 & 0.0327 \\
\hline 43 & Perfumes \& Cosmetics & 0.3442 & 0.4387 & 0.4531 & 0.1088 & 0.0144 \\
\hline 44 & Paints \& Varnishes & 0.2877 & 0.3851 & 0.4001 & 0.1124 & 0.0150 \\
\hline 45 & Soaps \& Detergents & 0.1209 & 0.1704 & 0.1868 & 0.0659 & 0.0164 \\
\hline 46 & Chemicals & 0.0527 & 0.1127 & 0.1376 & 0.0849 & 0.0249 \\
\hline 47 & Plastic Products & 0.2902 & 0.3816 & 0.3982 & 0.1080 & 0.0166 \\
\hline 48 & Petroleum Products & 0.3115 & 0.3407 & 0.3505 & 0.0390 & 0.0098 \\
\hline 49 & Cement & 0.1204 & 0.2223 & 0.2710 & 0.1505 & 0.0487 \\
\hline 50 & Glass \& Products & 0.2067 & 0.3690 & 0.3995 & 0.1927 & 0.0304 \\
\hline 51 & Non-Met. Mineral Pdts & 0.0038 & 0.0773 & 0.0961 & 0.0923 & 0.0189 \\
\hline 52 & Basic Metals & 0.0000 & 0.0523 & 0.0762 & 0.0762 & 0.0240 \\
\hline 53 & Metal Products & 0.0730 & 0.1396 & 0.1519 & 0.0790 & 0.0124 \\
\hline 54 & Iron \& Steel Remg. & 0.0000 & 0.0268 & 0.0349 & 0.0349 & 0.0081 \\
\hline 55 & Agricultural Machinery & -0.0785 & 0.0166 & 0.0289 & 0.1074 & 0.0123 \\
\hline 56 & Other Non-Elect. Mach. & 0.0000 & 0.0641 & 0.0824 & 0.0824 & 0.0183 \\
\hline 57 & Elect. Mach. & 0.0000 & 0.0821 & 0.0961 & 0.0961 & 0.0139 \\
\hline 58 & Bicycles & 0.0000 & 0.0800 & 0.1000 & 0.1000 & 0.0199 \\
\hline 59 & Transport/1s & 0.0032 & 0.0979 & 0.1125 & 0.1093 & 0.0146 \\
\hline 60 & Ship Building & 0.0000 & 0.0524 & 0.0654 & 0.0654 & 0.0130 \\
\hline 61 & Transport Eqpt. ss & 0.0000 & 0.0236 & 0.0413 & 0.0413 & 0.0177 \\
\hline 62 & Office Equipment & 0.0000 & 0.0847 & 0.0991 & 0.0991 & 0.0144 \\
\hline 63 & Sports Goods & 0.0000 & 0.0545 & 0.0669 & 0.0669 & 0.0124 \\
\hline 64 & Surgical Instruments & 0.0000 & 0.0406 & 0.0545 & 0.0545 & 0.0139 \\
\hline 65 & Other Large-scale Mfg. & 0.4709 & 0.5182 & 0.5337 & 0.0629 & 0.0156 \\
\hline 66 & Other Small-scale Mfg. & 0.0000 & 0.0806 & 0.0954 & 0.0954 & 0.0148 \\
\hline 67 & Low-cost Resid. Bldgs & 0.0000 & 0.0664 & 0.0808 & 0.0808 & 0.0144 \\
\hline 68 & Luxurious Resid. Bldgs & 0.0000 & 0.0808 & 0.0954 & 0.0954 & 0.0146 \\
\hline 69 & Rural Buildings & 0.0000 & 0.0291 & 0.0372 & 0.0372 & 0.0081 \\
\hline 70 & Factory Buildings & 0.0000 & 0.0887 & 0.1028 & 0.1028 & 0.0141 \\
\hline 71 & Public Buildings & 0.0000 & 0.0664 & 0.0763 & 0.0763 & 0.0099 \\
\hline
\end{tabular}


Table 3 - (Continued)

72 Roads

73 Infrastructure

$\begin{array}{llllll} & 0.0000 & 0.0230 & 0.0287 & 0.0287 & 0.0057 \\ & 0.0000 & 0.0762 & 0.1262 & 0.1262 & 0.0499 \\ \text { Trade } & 0.0000 & 0.0131 & 0.0348 & 0.0348 & 0.0217 \\ & 0.0000 & 0.0815 & 0.2160 & 0.2160 & 0.1344 \\ & 0.4023 & 0.4158 & 0.5437 & 0.1414 & 0.1279 \\ & 0.0000 & 0.0029 & 0.0120 & 0.0120 & 0.0092 \\ & 0.0000 & 0.0768 & 0.0836 & 0.0836 & 0.0068 \\ & 0.0000 & 0.0874 & 0.1108 & 0.1108 & 0.0360 \\ & 0.0000 & 0.0079 & 0.0973 & 0.0973 & 0.0098 \\ & 0.0000 & 0.0596 & 0.0699 & 0.0699 & 0.0102 \\ & 0.0000 & 0.0233 & 0.0342 & 0.0342 & 0.0120 \\ & 0.0000 & 0.0105 & 0.0345 & 0.0345 & 0.0240 \\ & 0.0025 & 0.0335 & 0.0438 & 0.0413 & 0.0103 \\ & 0.0000 & 0.1414 & 0.0455 & 0.0455 & 0.0314 \\ & 0.0030 & 0.0058 & 0.0157 & 0.0127 & 0.0100\end{array}$

74 Ownership of Dwellings

75 Electricity

76 Gas

77 Wholesale \& Retail Trade

78 Road Transport

79 Rail Transport

80 Air Transport

81 Water Transport

82 Television

83 Radio

84 Phone, Teleg. \& Post

85 Banking \& Insurance

86 Government

87 Services

$$
\text { Note: } \begin{aligned}
t_{e} & =t_{e(d)}+t_{e(m)} \\
\bar{t}_{e} & =\bar{t}_{e(d)}+\bar{t}_{e(m)} \\
\bar{t}_{\text {diff }} & =\bar{t}_{e}-t_{\text {nom }}
\end{aligned}
$$

See also notes to Tables 1 and 2 .

agricultural commodities, $\bar{t}_{\text {diff }}$ is quite low - less than 2 percent of the purchaser price. However, it may be noted that the effective subsidy on wheat is only twothirds of the nominal subsidy. Most manufactured food items have a value of $\bar{t}_{\text {diff }}$ ranging from 4 percent in the case of 'tea' to over 9 percent for 'beverages'. Clothing items are also considerably affected by the direct and indirect taxation of inputs, $\bar{t}_{\text {diff }}$ varying from 6 percent for 'cotton yarn' to 91.5 percent for 'silk and synthetics' and almost 15 percent of the purchaser price of 'made up garments'. Other consumer items such as footwear and paper fall in the same range. Intermediate goods generally reflect a substantial effect of the direct and indirect taxation of inputs and the range is on average between 10 percent to 20 percent of the purchaser price. For instance $\vec{t}_{d \text { iff }}$ for 'electricity' is over 21 percent. In the case of 'fertilizers', a $\bar{t}_{d \text { iff }}$ of 12 percent implies that the effective subsidy is 43 percent lower than the nominal subsidy.

The inclusion of the capital stock matrices has had a small, though significant impact on purchaser prices. For agricultural commodities $\bar{t}_{e}-t_{e}$ is less than one 
percent of the purchaser price, although this constitutes over 50 percent of $\bar{t}_{d i f f}$ for 'wheat' and 'cotton'. For most other goods $\bar{t}_{e}-t_{e}$, lies between one percent and 2 percent of the purchaser price, and exceeds 2 percent for several highly capitalintensive sectors such as 'large-scale cotton textiles', 'fertilizers', 'chemicals', 'cement', and 'basic metals'. The highest contribution of the capital stock to effective taxes is in the cases of 'electricity' and 'gas', where more than 10 percent of the price is accounted for in this manner.

We have seen that the 'effective tax' differs greatly from the nominal tax implicit in revenue collections. This exercise may be of use to policy-makers in describing the possibly unintended consequences of tax policy. An area in which it could be of direct benefit is that of the setting appropriate levels of export subsidies. The effective taxes could be used to provide a quantification of the direct and indirect taxation of domestically produced goods for export. Under GATT these taxes could be rebated through an export subsidy. Many developed countries achieve this rebate by zero-rating of exports for VAT, thus allowing exporters to reclaim the tax paid in inputs.

\section{POLICY AND CONCLUSIONS}

In this paper we have presented a method of approaching a tax reform, in terms of consequences for households, government revenue and production, which could provide a Ministry of Finance with the tools for continuous monitoring of the economy and evaluation of particular proposals for reform. The data requirements are not particularly demanding and should be within the competence of countries like Pakistan which have fairly well-established statistical offices and research facilities.

The empirical part of this paper concentrates on 'effective taxes', or the tax element in the price of final goods. These estimates, which are an essential ingredient in the analysis of reform, are of interest in themselves since they illustrate the possibly unintended consequences of government policy. The considerable divergence between nominal and effective tax rates described above illustrates this point and underlines the danger in relying on nominal or statutory tax rates on commodities as indicators of the extent to which the goods are actually taxed. Important elements in these taxes arising through inputs come from the taxation of imports of current inputs, taxation of capital goods (imported or otherwise) and, in particular, excises on domestically produced inputs.

The theory presented here, together with the effective taxes, forms the first part of our analysis of tax reform. In subsequent papers we shall use this theory and the effective tax calculations to identify desirable directions of reform from the point of view of revenue and consumption. We shall then bring in costs and benfits of reform which flow from production changes, using a system of shadow prices. 


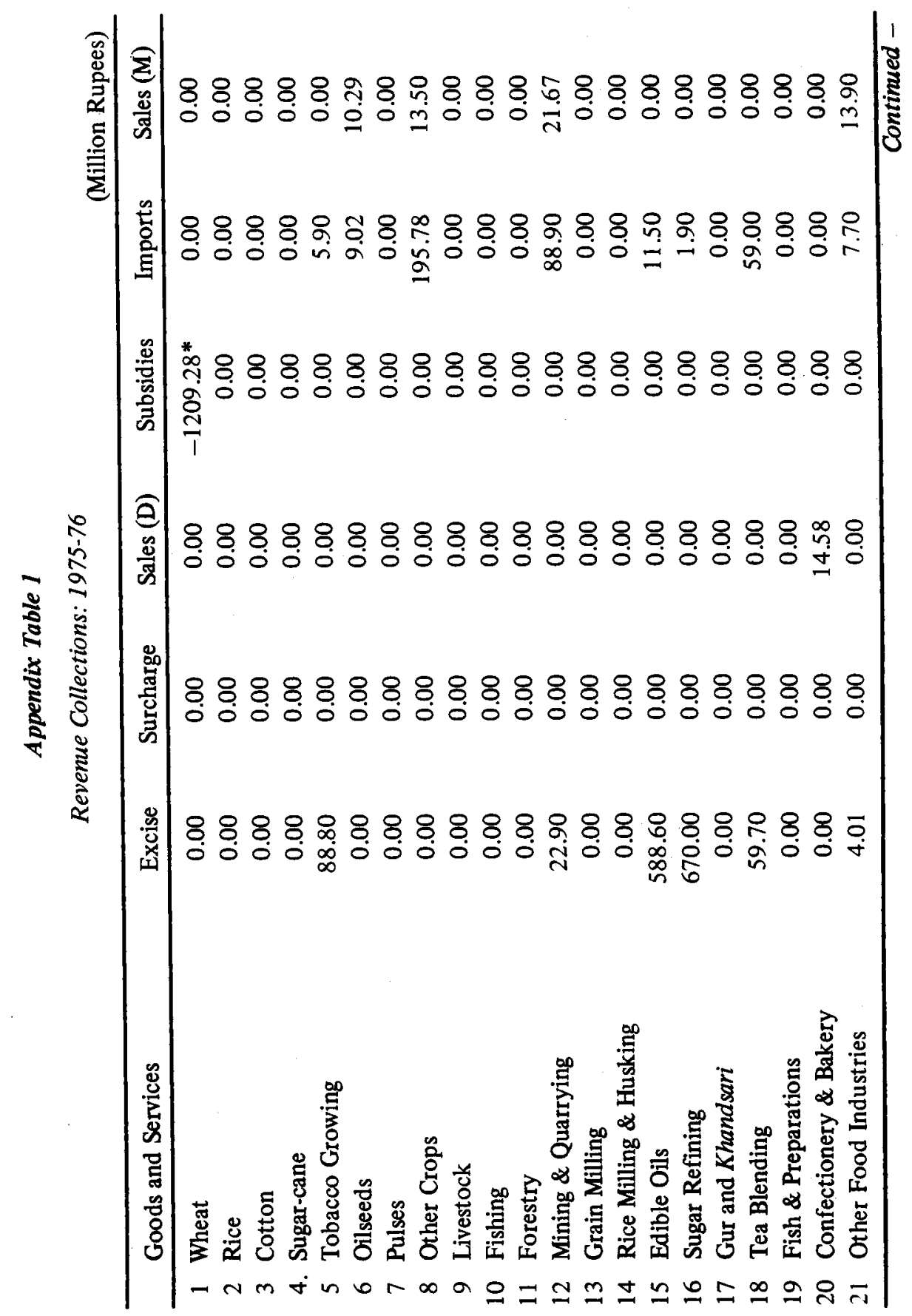




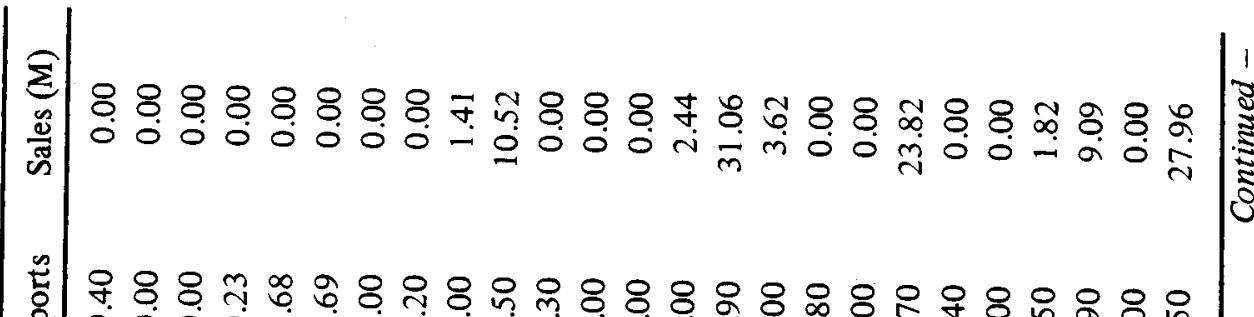

$$
\begin{aligned}
& \text { 哯 } \\
& \text { 8 }
\end{aligned}
$$

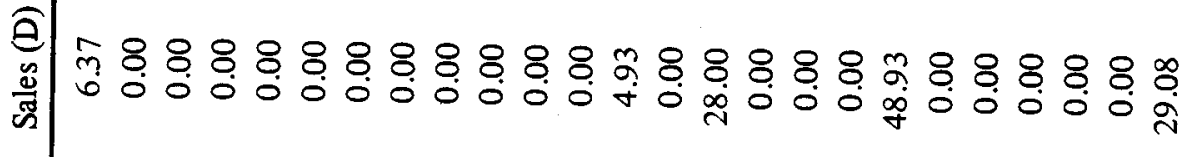

$$
\begin{aligned}
& \text { 总 }
\end{aligned}
$$

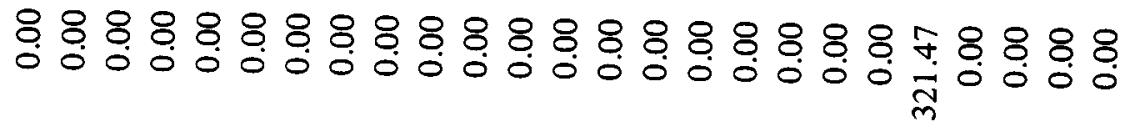

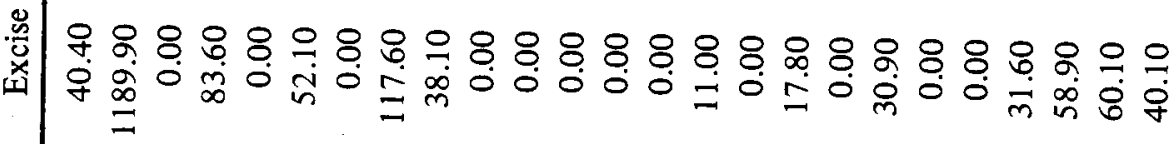




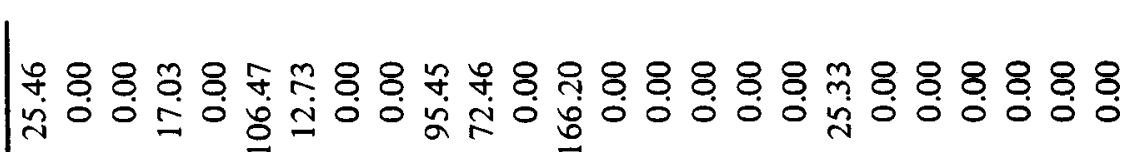

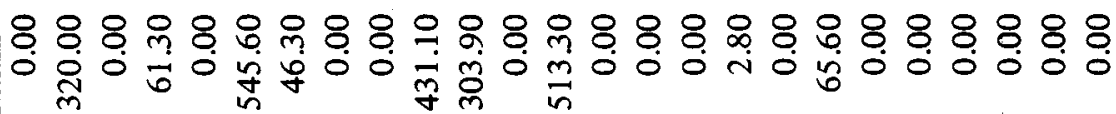

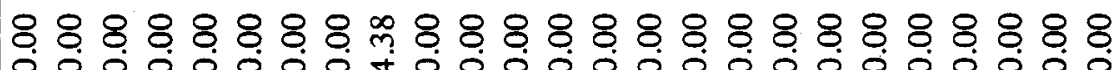
0000000040000000000000000

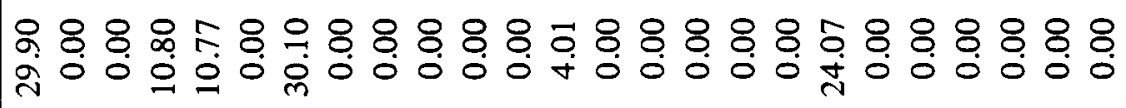

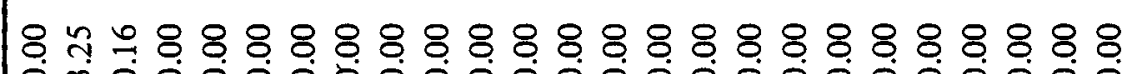
0 h0.0000000000000000000

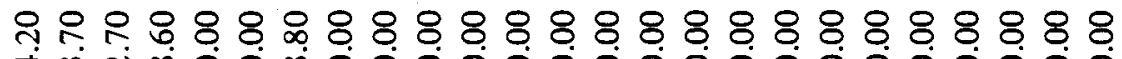

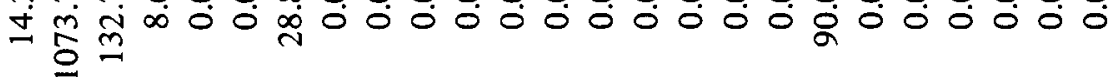

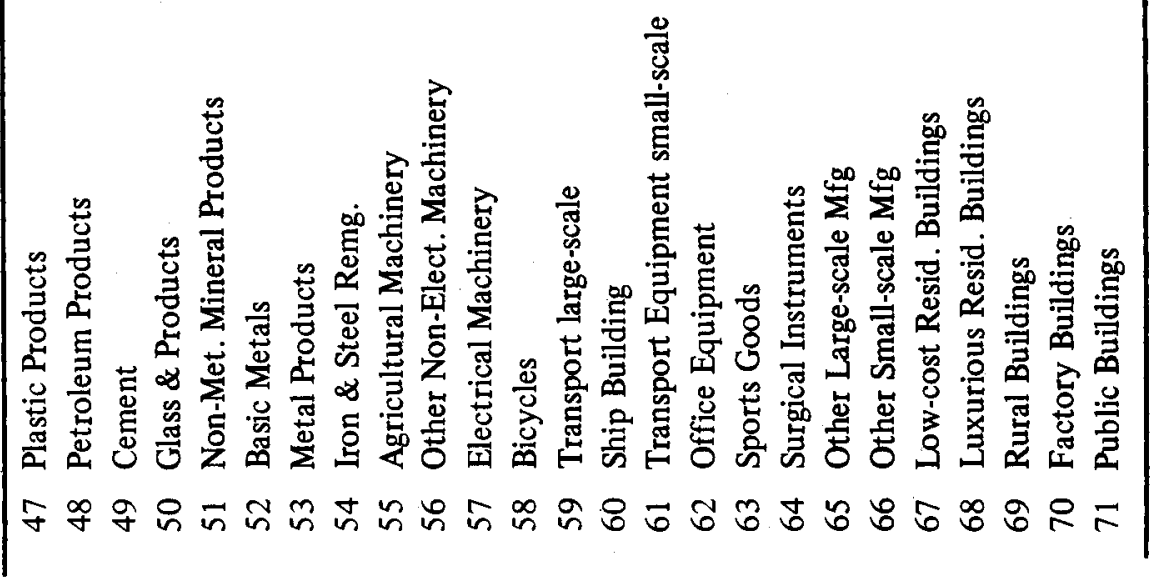




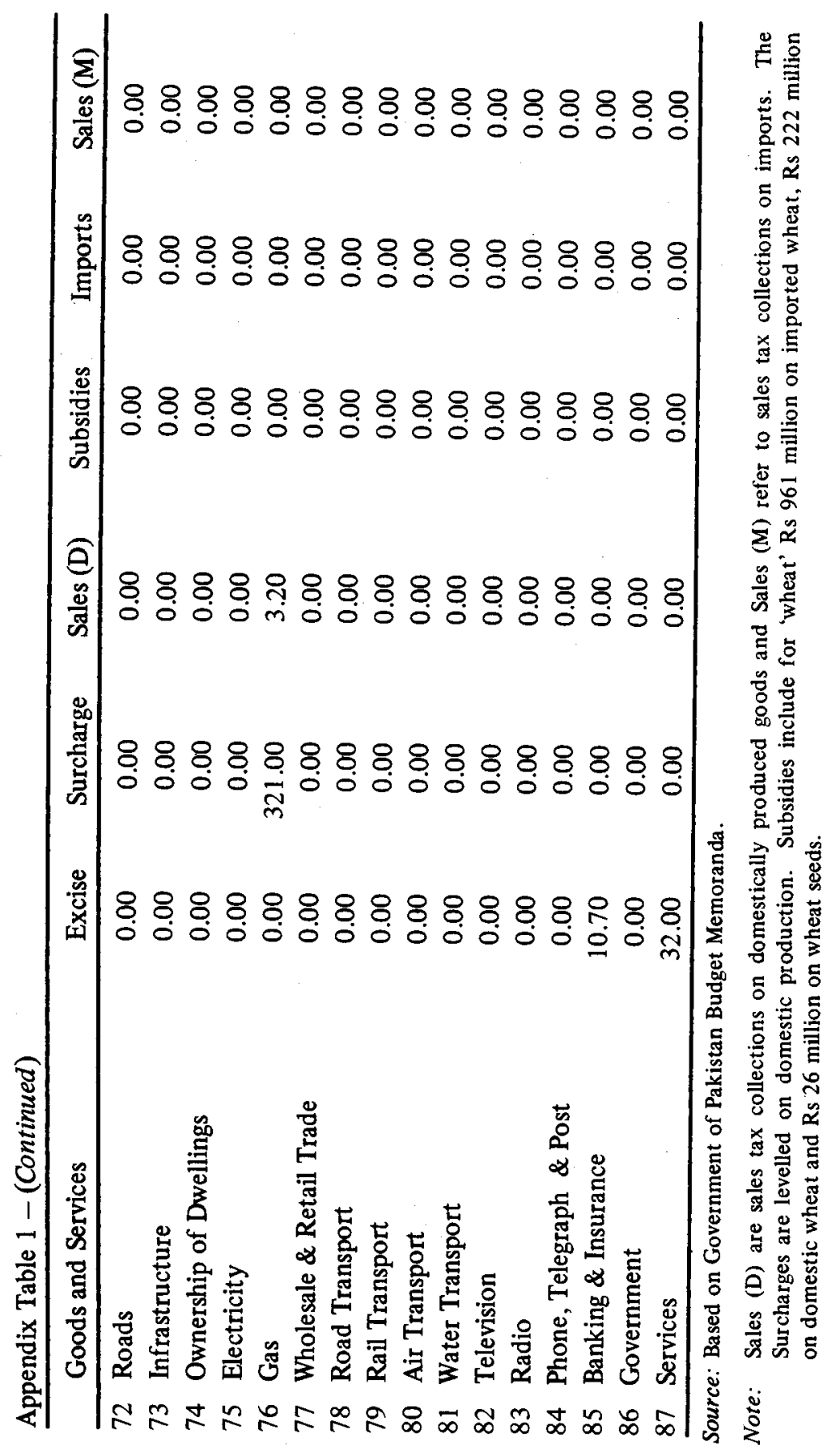


Appendix Table 2

Accounting Ratios for Exports

\begin{tabular}{lccc}
\hline Commodity & $\begin{array}{c}\text { Value of Exports } \\
\text { (Million Rupees) }\end{array}$ & $\begin{array}{c}\text { Export Tax } \\
\text { (Million Rupees) }\end{array}$ & $\begin{array}{c}\text { Accounting } \\
\text { Ratio }\end{array}$ \\
\hline Rice & 2479.1 & 241.2 & 1.1078 \\
Cotton (Raw) & 980.5 & 330.0 & 1.5073 \\
Leather & 595.5 & 80.0 & 1.1551 \\
Cotton Waste & 1422.3 & 10.0 & 1.0071 \\
\hline
\end{tabular}

Source: [12].

\section{REFERENCES}

1. Ahmad, S. E., and N. H. Stern. "Alternative Sources of Government Revenue". In D.M.G. Newbery and N. H. Stern (eds.), The Theory of Taxation for Developing Countries. OUP and World Bank. 1986.

2. Ahmad, S. E., and N. H. Stern. "Effective Taxes and Tax Reform in India". 1983. (DERC Discussion Paper No. 25)

3. Ahmad, S. E., and N. H. Stern. "On the Sensitivity of Indirect Tax Systems: An Application to India". 1981. (DERC Discussion Paper No. 1)

4. Ahmad, S. E., and N. H. Stern. Tax Reform and Development. Cambridge: Cambridge University Press. (Forthcoming)

5. Ahmad, S. E., and N. H. Stern. "The Theory of Reform and Indian Indirect Taxes". Journal of Public Economics. Vol. 25, No. 3. 1984. pp. 259-95.

6. Dreze, J. "On the Choice of Shadow Prices for Project Evaluation". Ph.D. Thesis, Indian Statistical Institute. 1983.

7. Dreze, J., and N. H. Stern. "The Theory of Cost-benefit Analysis". In A. Auerbach and M. Feldstein (eds.), Handbook of Public Economics. (Forthcoming)

8. Irfan, M. "Shifting and Incidence of Indirect Taxes on Tobacco and Petroleum Products in Pakistan". Pakistan Development Review. Vol. XIII, No. 1. Spring 1974. pp. 66-87.

9. Jeetun, A. "Pakistan's Tax System: Structure Elasticity, Incidence and Fiscal Effort”. Ph.D. Thesis, Karachi University. 1980.

10. Naqvi, B. "Shifting of Indirect Taxes: A Further Study". Pakistan Development Review. Vol. XIV, No. 2. Summer 1975. pp. 174-184.

11. Pakistan. Federal Bureau of Statistics. National Accounts of Pakistan (Product and Expenditure). Karachi. 1982. 
12. Pakistan. Federal Bureau of Statistics. Ten Years of Pakistan Statistics 1972-82. Karachi. 1983.

13. Pakistan. Ministry of Finance. Explanatory Memorandum on the Budget 1976-77. Islamabad. 1976.

14. Radhu, G. M. "The Relation of Indirect Tax Changes to Price Changes in Pakistan". Pakistan Development Review. Vol. V, No. 1. Spring 1965. pp. 54-63.

15. Saleem, Mohammad et al. "Revised PIDE Input-Output Table for Pakistan's Economy: 1975-76". Islamabad: Pakistan Institute of Development Economics. 1983. (Research Report Series, No. 139)

16. Seade, J. "Profitable Cost Increases and the Shifting of Taxation: Equilibrium Responses of Markets in Oligopoly". Coventry: University of Warwick. 1985. (Warwick Economic Research Paper No. 260)

17. Squire, L., I.M.D. Little and M. Durdag. "Shadow Pricing and Macro-economic Analysis: Some Illustrations for Pakistan". Pakistan Development Review. Vol. XVIII, No. 2. Summer 1979. pp. 89-112.

18. Stern, N. H. "The Effects of Taxation, Price Control and Government Contracts in Oligopoly and Monopolistic Competition". Coventry: University of Warwick, Development Economics Research Centre. 1985. (Mimeographed)

19. Stern, N. H. "Optimum Taxation and Tax Policy". International Monetary Fund Staff Papers. July 1984. pp. 339-378. 